\title{
GOVERNANÇA CORPORATIVA: TEORIA E BENEFÍCIOS DE SUA APLICAÇÃO NA GESTÃO
}

\author{
Nilton José Coelho Neto ${ }^{1}$
}

RESUMO: Este trabalho apresenta a conceituação de governança corporativa, identificando-a com as boas práticas de gestão corporativa. Logo em seguida este trabalho apresenta o histórico da governança corporativa no mundo, alertando que as técnicas já existiam mas não eram utilizadas até o momento em que algumas fraudes ocorrem e governança corporativa passa a ser legalmente obrigatória para um grupo de empresas. Em seguida apresenta a criação do Instituto Brasileira de Gestão Corporativa com o ponto de partida para o debate sobre a aplicação de boas práticas de gestão no Brasil. Em seguida apresenta-se os benefícios da utilização da governança corporativa, explicando que a criação de um conselho fiscal, de um comitê de auditoria e principalmente de um conselho de administração são importantes para a empresa conseguir ser mais efetiva. A utilização de técnicas de governança permite a empresa ser mais transparente, e entregar a gestores, sócios e investidores, relatórios mais assertivos sobre a situação da empresa, possibilitando que investidores consigam avaliar melhor a situação da empresa.

Palavras-chave: Governança Corporativa. Administração. IBGC. Lei Sarbanes-Oxley.

ABSTRACT: This paper presents the concept of corporate governance, identifying it with good corporate management practices. Soon after this work presents the history of corporate governance in the world, warning that the techniques already existed but were not used until the moment when some frauds occur and corporate governance becomes legally mandatory for a group of companies. Then he presents the creation of the Brazilian Institute of Corporate Management as the starting point for the debate on the application of good management practices in Brazil. Next, the benefits of using corporate governance are presented, explaining that the creation of a fiscal council, an audit committee and especially a board of directors are important for the company to be more effective. The use of governance techniques allows the company to be more transparent, and deliver more assertive reports on the company's situation to managers, partners and investors, enabling investors to better assess the company's situation.

Keywords: Corporate Governance. Adminitration. IBGC. Law Sarbanes-Oxley.

\footnotetext{
${ }^{1}$ Bacharel em Ciências Contábeis e Licenciado em História. Especialista em Finanças Corporativas, Gestão Escolar e História das Religiões. Mestrando em Administração pela Must University. E-mail: niltonjosecoelho@gmail.com.
} 


\section{INTRODUÇÃO}

Este trabalho tem como objetivo apresentar a importância da governança corporativa e os benefícios que a utilização de técnicas pode trazer à gestão de empresas. Desde a década de 90 do século passado, os investimentos no mercado de valores mobiliários têm se intensificado e, com isso, houve o aumento da necessidade de informações e de relatórios emitidos pelas empresas que demonstrem credibilidade e boa gestão corporativa. A governança corporativa atende a essa necessidade por meio da utilização de boas práticas em administração.

A adoção de práticas de governança começou nos EUA por volta da década de 1950, no entanto, teve sua aceleração após os escândalos financeiros de 200I, quando as empresas Enron, Xerox e WorldCom adulteraram suas demonstrações financeiras e, ao serem descobertas essas adulterações, formaram-se crises econômicas. A união de dois deputados, um republicano e um democrata, deu origem à Lei Sarbanes-Oxley que obrigou a utilização de governança para um grande grupo de empresas. Em paralelo, o mesmo processo ocorreu na Europa e na Inglaterra, e com isso foram se aprofundando as diretrizes legais, ao redor do mundo, que estimulam as boas práticas corporativas.

Em seguida este trabalho apresenta o cenário da governança corporativa no Brasil, colocando o final da década de 9o, com a criação do Instituto Brasileiro de Governança Corporativa, como o início dos debates necessários para a mudança da legislação e a obrigação das empresas em sociedade anônima de aplicar as técnicas.

O trabalho se encerra demonstrando os benefícios da aplicação da Governança, listando os órgãos que são criados com a aplicação das boas práticas de gestão e no que eles contribuem para a gestão empresarial.

Para alcançar os objetivos propostos, este trabalho utiliza pesquisa bibliográfica e qualitativa. Bibliográfica porque, conforme Boccato:

A pesquisa bibliográfica busca a resolução de um problema (hipótese) por meio de referenciais teóricos publicados, analisando e discutindo as várias contribuições científicas. Esse tipo de pesquisa trará subsídios para o conhecimento sobre o que foi pesquisado, como e sob que enfoque e/ou perspectivas foi tratado o assunto apresentado na literatura científica. Para tanto, é de suma importância que o pesquisador realize um planejamento sistemático do processo de pesquisa, compreendendo desde a definição temática, passando pela construção lógica do trabalho até a decisão da sua forma de comunicação e divulgação. ( Boccato, 2006, p.266) 
Este trabalho é qualitativo no sentido de que perpassará por conceitos sem se dedicar a medições ou ensaiar pesquisa que se atenha a quantitativos.

Em resumo, este trabalho inicia conceituando governança, passando pelo histórico desta prática no mundo e depois no Brasil e, ao final, apresenta os benefícios da utilização da governança nas empresas.

\section{DESENVOLVIMENTO}

\section{CONCEITOS DE GOVERNANÇA CORPORATIVA}

A Governança Corporativa é definida por alguns autores como sendo um compilado de convenções e regras que visam estabelecer o bom relacionamento entre os gestores de uma corporação ou empresa e seus acionistas. Em tese, Governança Corporativa significa transparência na gestão para atender as necessidades daqueles que colocaram dinheiro na empresa. Para Steinberg (2003), a nomenclatura Governança Corporativa seria uma tradução mal feita do inglês Corporate Governance. Sendo que Governance se origina do latim Gubernare, que significa governar ou dirigir. Como corporate tem ligação direta com corporation, a expressão teria em seu cerne a forma com a qual os acionistas governam uma empresa.

Governança corporativa é um tema relativamente recente, originado por volta da década de 1950 nos Estados Unidos e, por isso, ainda existe a construção do conceito por diversos autores. Silveira (2002), de forma muito simples, define Governança Corporativa como um conjunto de mecanismos que são utilizados na tomada de decisão corporativa de modo a maximizar valores a longo prazo de um negócio. Este conceito de que Governança Corporativa é um conjunto de ferramentas ou mecanismos é compartilhado por diversos autores, como por exemplo, Lethbridge:

Um sistema de governança corporativa é composto pelo conjunto de instituições, regulamentos e convenções culturais, que rege a relação entre as administrações de empresas e os acionistas ou outros grupos às quais as administrações, de acordo com o tipo de modelo, devem prestar contas. (Lethbridge,1997,p.210)

Barbosa (2008) também elucida o conceito alertando que governança corporativa seria um sistema de poderes estruturados que coordenam mecanismos utilizados na direção e no controle da empresa. De acordo com a Comissão de Valores Mobiliários (2002), governança corporativa seria um grupo de práticas com objetivo de aprimorar o desempenho de uma empresa, de proteger as partes interessadas, tais como acionistas, empregadores e 
credores. Governança corporativa envolve transparência, equidade de tratamento de acionistas e prestação de contas.

Álvares et al. (2008) ressaltam que foi o desenvolvimento do mercado de capitais que influenciou a adoção de práticas de governança corporativa.

Em resumo, a necessidade de informações para o trade-off investir ou não em uma empresa foi a grande impulsionadora do desenvolvimento recente em governança corporativa. NesSe sentido, as corporações passaram a adotar práticas de controle e transparência de forma a subsidiar o processo de tomada de decisão de investimento.

De acordo com o IBGC (2015), são quatro os principais fundamentos da governança corporativa: transparência, equidade, prestação de contas e responsabilidade corporativa.

Ainda de acordo com o IBGC (2015), transparência seria a intenção de disponibilizar informações de interesse para as partes interessadas, e não somente aquelas exigidas pela legislação. Equidade teria a ver com isonômia entre sócios e demais interessados. Prestação de contas é a ação de prestar contas de modo claro e conciso. Responsabilidade corporativa se justifica pela necessidade dos gestores de zelar pela viabilidade econômico-financeira da organização.

Parece estranho que existam regras que preguem o que deveria ser padrão em qualquer corporação, no entanto, deve-se imaginar que em anos anteriores as empresas eram consideradas empreitadas individuais e, por isso, muitas empresas carregavam o nome de seus fundadores como identificação e, por conta disso, a divulgação de informações não era uma prática corriqueira.

\section{GOVERNANÇA CORPORATIVA NO MUNDO: ASPECTOS GERAIS}

No capítulo anterior viu-se que as técnicas de governança são usadas nos EUA desde aproximadamente 1950, no entanto, não havia concisão e nem obrigatoriedade nesse uso. De acordo com Borgerth (2007), foi somente através da promulgação da Lei Sarbanes-Oxley (SOX), em 2002, que foi estabelecida a mudança legal obrigando o uso de aspectos de governança. Antes disso, as leis vigentes eram de 1933 e 1934.

O estabelecimento da Lei SOX se deu após o descobrimento de uma série de escândalos empresariais. De acordo com o Jornal contábil (2016), houve uma série de escândalos contábeis nos EUA que fizeram com que a lei SOX fosse sancionada, a citar, o 
caso da Enron, Xerox e da Worldcom. O caso da Enron ocorreu em 2002, sendo que nesta época ela era considerada a sétima maior empresa do ramo nos Estados Unidos, e, de uma hora para outra, pediu concordata. Isso foi um choque para todo o mercado, pois a empresa valia cerca de US\$ 64 bilhões em Janeiro de 200I.

De acordo com Crepaldi (2013), Oxley era um republicano e Sabarnes era democrata, deputados criadores da lei Sarbanes-Oxley ou lei SOX, que representou uma reação às manipulações dos balanços financeiros e das fraudes contábeis. Como visto, a necessidade de regulação de algo que afetou fortemente a economia mundial uniu os dois principais partidos americanos. A crise gerada por estas fraudes afetou fortemente a economia até o ano de 2015 .

Ainda de acordo com Crepaldi (2013), essa lei apresentou ideias claras sobre aspectos duvidosos, já que o objetivo era determinar a responsabilidade dos executivos e gestores financeiros (diretores) sobre a apresentação de informações financeiras e a manutenção de controles que garantam relatórios adequados.

Cabe destacar que a Lei Sox, por mais que influencie várias legislações e procedimentos ao redor do mundo, não é o único modelo de governança existente. Considera-se a existência de dois modelos clássicos: o primeiro nomeado de Anglo-saxão e utilizado nos EUA e Reino Unido, e o segundo, o nipo-germânico que é o utilizado no Japão, Alemanha e em grande parte dos países da Europa.

Silveira (2010) afirma que foi nos Estados Unidos, na década de 1980, que a Governança Corporativa surgiu de forma efetiva. Este é o país com o maior mercado de capitais, com maior volume negociado e que possui a maior quantidade de empresas listadas. Por este motivo, geralmente é dos EUA que as melhores práticas em governança são ditadas.

De acordo com Garcia (2007), a Inglaterra inseriu a governança corporativa como prática após a ocorrência de escândalos financeiros. O objetivo era fortalecer a confiança no mercado.

Silveira (2010) nos alerta que o modelo de governança implementado na Alemanha é voltado para os EUA e a Inglaterra, já que procuram manter a gestão aberta à participação de acionistas.

Percebe-se, portanto, que os motivos das duas principais referências em governança corporativa estão atrelados a casos de escândalos contábeis e financeiros. Ou seja, por mais 
que as ferramentas já existissem antes desses problemas, elas não eram aproveitadas em toda a sua capacidade e tiveram como detonador de uso os escândalos que preocuparam as economias destes países. Já os demais países acabaram por implementar a governança corporativa por ser considerada boa prática nos Estados Unidos, lar de muitos dos investidores das empresas desses países. Alemanha e Japão, por exemplo, foram arrasadas durante a Segunda Grande Guerra e se tornaram dependentes do capital americano, sendo, por isso, necessário se adequar às boas práticas destes países.

\section{GOVERNANÇA CORPORATIVA NO BRASIL}

Por muitos anos o mercado de capitais no Brasil foi incipiente, já que as grandes empresas eram estatais e as empresas privadas que existiam, no geral, não buscavam se capitalizar através da venda de ações na bolsa.

Silveira (2010) concorda com o pensamento ao dizer que no século XX o mercado de capitais no Brasil era inexpressivo.

Por conta disso não havia muito interesse pela execução de práticas que assegurassem aos investidores alguma segurança sobre a qualidade de seus investimentos. Para $\mathrm{Zdanowics}$ (2012), isso começa a se alterar em 1995 com a criação do Instituto Brasileiro de Governança Corporativa (IBGC), voltado à divulgação de boas práticas de governança, permitindo, então, o acompanhamento da empresa e da forma de gestão através de uma diretoria executiva. Silveira (2010) também destaca que o grande estímulo à utilização de técnicas de governança corporativa se deu na década de 90 com a criação do IBGC, que era o efetivo responsável pelas atividades de gestão corporativa.

O mesmo Silveira (20I0) alerta que a governança corporativa foi sendo acrescida ao mercado a partir da adoção de uma crença maior em investimentos que possuam um controle financeiro sistemático.

Ainda para Silveira (2010, p. 179), por volta do ano 2000, "um estudo conduzido pelo Banco Mundial em parceria com a consultoria McKinsey ganhou ampla repercussão nos meios empresariais locais ao indicar que os investidores estariam dispostos a pagar um prêmio substancial por ações de empresas com maior transparência e prestação de contas.”

De fato, existem diversos benefícios em empresas que utilizam de métodos de governança, conforme a seguir: 
Existem dois potenciais benefícios principais que a boa governança pode acarretar às empresas: os benefícios externos, associados à maior facilidade de captação de recursos e à redução do custo de capital; e os benefícios internos, vinculados ao aprimoramento do processo decisório na alta gestão. (SILVEIRA, 20Io, p. 7).

Um ponto que é muito atrativo para investidores é a redução do custo do capital, pois acaba diminuindo os riscos empresariais, no entanto, para conseguir essa redução são necessários investimentos em governança corporativa, mas a implantação de um sistema mais bem estruturado com relatórios bem delineados possui um custo. Esse custo deve ser avaliado, mas considerado como sendo um investimento, já que, conforme dito anteriormente, a utilização de boas práticas pelas empresas é considerada fator determinante para o investimento por parte de muitos investidores.

\section{PRINCIPAL BENEFÍCIO DA GOVERNANÇA CORPORATIVA - MELHORA DA GESTÃO}

O principal benefício da implementação da governança corporativa é a melhora no padrão geral da gestão empresarial. A empresa precisa se reestruturar, começando pelas pessoas que pensam o negócio, ou seja, aquelas que criam as ferramentas de gestão e que moldam a empresa. São essas pessoas, que formam a direção da empresa, que tem a obrigação de dar a direção a ser tomada pelo pessoal que irá executá-la.

Vale destacar a definição abaixo a respeito de governança corporativa:

\footnotetext{
Modelo de gestão que, a partir da otimização das interações entre acionistas ou cotistas, Conselhos - de administração e Fiscal, Auditorias - Interna e Externa e Diretoria Executiva, proporciona a adequada sustentação para o aumento da atratividade da empresa no mercado - Financeiro e Comercial - e conseqüentemente incremento no valor da empresa, redução do nível de risco e maior efetividade da empresa ao longo do tempo (OLIVEIRA, 2007, p. 9)
}

A argumentação de Oliveira (2007) deixa claro que uma combinação de uma boa governança com uma gestão estratégica bem alinhada é capaz de gerar valor para a empresa. Existem ferramentas preestabelecidas no processo de Governança que auxiliam a empresa a assegurar qualidade em sua gestão, a nomear, conselho fiscal, auditoria independente e o conselho de administração, também conhecido como boards.

É necessário explicar um pouco cada um dos setores que são determinados pela governança corporativa como sendo muito necessários para as boas práticas empresariais, começando pelo conselho fiscal. 
Como o próprio nome define, o conselho fiscal é um órgão fiscalizador que, de acordo com as boas práticas, deve ser eleito pelos acionistas e, por ser um órgão eleito, espera-se que seja independente.

Por mais que seja opcional em organizações enquadradas como sociedades limitadas, o conselho fiscal é um órgão essencial para as boas práticas corporativas, mais que isso, nessas sociedades ele é obrigatório.

De acordo com Alvares, Giacometti e Gusso (2008), o conselho fiscal possui as seguintes responsabilidades:

- Fiscalização: analisar a gestão, avaliar os riscos e a estrutura de controle interno. Garantir o cumprimento de obrigações legais, contratuais e estatuárias.

- Financeira: ter ciência da origem de recursos financeiros da organização e de todas as aplicações realizadas, bem como analisar as demonstrações financeiras, emitindo parecer sobre elas.

- Documental: analisar contratos realizados pela organização.

- Interação com outros órgãos de governança.

Como visto, o conselho fiscal possui uma série de responsabilidades que vão desde fiscalizar diretamente a gestão da empresa, avaliando o risco das decisões tomadas e a qualidade nos controles implementados por esta gestão, até o ponto de analisar os contratos que são firmados pela empresa. Trata-se, então, de um órgão essencial para garantir a implementação de boas práticas nas empresas. Por mais que esse órgão seja obrigatório somente em sociedades anônimas, entende-se que é essencial também em sociedades limitadas pois, através dos pareceres emitidos por esse órgão, tem-se noção da qualidade na gestão financeira da empresa.

Outro órgão determinado pela governança corporativa é o Comitê de Auditoria. Esse órgão tem a função de analisar os relatórios das auditorias realizadas, dos relatórios emitidos e dos cenários de risco. É um comitê interno, preestabelecido pela empresa e composto, geralmente, por colaboradores da empresa que possuem visível conhecimento sobre todos os processos internos.

O terceiro órgão a ser examinado é a principal ferramenta estimulada pelas boas práticas em administração, o conselho de administração. A fundamentação da existência de um conselho administrativo, de acordo com o IBGC, é: 
O conselho de administração é o órgão colegiado encarregado do processo de decisão de uma organização em relação ao seu direcionamento estratégico. Ele Exerce o papel de guardião dos princípios, valores, objeto social e do sistema de governança da organização, sendo seu principal componente. Além de decidir os rumos estratégicos do negócio, compete ao conselho de administração, conforme o melhor interesse da organização, monitorar a diretoria, atuando como elo entre esta e os sócios. (IBGC, 2015, p. 39)

O conselho de administração é um dos principais contributos para o bom resultado empresarial. Em sua cartilha sobre governança corporativa, a CVM (2002, p.4) cita que o "conselho de administração deve atuar de forma a proteger o patrimônio da companhia, perseguir a consecução de seu objeto social e orientar a diretoria a fim de maximizar o retorno do investimento, agregando valor ao empreendimento".

É importante destacar que governança corporativa, para além de melhorar a gestão administrativa, traz importantes ganhos em relação à parte financeira da empresa. Tanto o comitê de auditoria quanto o conselho fiscal acabam zelando por relatórios e pelas decisões financeiras, auditando o processo e emitindo pareceres sobre as decisões tomadas que envolvam o financeiro da empresa.

Ademais, a aplicação de técnicas de governança, por conta de todos os processos elencados, aumenta a transparência e eficiência da empresa e, como conseqüência, melhora a imagem para seus sócios, mas, não só, também para investidores interessados em investir em empresas. Como a entrada de capital novo é sempre bem-vinda, encara-se que ela é também uma das conseqüências da utilização dos princípios de governança corporativa.

\section{CONSIDERAÇÕES FINAIS}

Entende-se que os objetivos do trabalho foram atendidos, pois no seu decorrer foi possível avaliar os principais conceitos ligados à área de governança. A conceituação de governança corporativa deixa claro a importância da aplicação destes princípios na gestão da empresa. O trabalho também apresentou o histórico da gestão financeira, sua origem nos principais centros financeiros do mundo, apresentando os Estados Unidos e Inglaterra como principais difusores das técnicas. Foi caracterizada a lei Sarbannes-Oxley como o regulador legal da aplicação de governança nos EUA. Em seguida apresentou-se o cenário da governança corporativa no Brasil e o principal agente incentivador das boas práticas em administração no Brasil. Ao término apresentou-se os benefícios gerais da aplicação de governança corporativa. Indica-se para trabalhos futuros o estudo de um case de aplicação 
de governança em uma corporação de forma a trazer o antes e depois da aplicação das técnicas e os ganhos efetivos que a corporação teve.

\section{REFERÊNCIAS BIBLIOGRÁFICAS}

ÁLVARES, E. et al. Governança corporativa: um modelo brasileiro. Rio de Janeiro: Elsevier, 2008.

BARBOSA, V. Níveis de governança corporativa: Rentabilidade e valorização. 2008. 69 f. TCC (Graduação) - Curso de Administração, Escola de Administração, Universidade Federal do Rio Grande do Sul, Porto Alegre, 2008. Disponível em: https://lume.ufrgs.br/handle/10183/17310. Acesso em: i5 mar. 2021.

CREPALDI, S.. Auditoria Contábil: Teoria e prática. 9. ed. São Paulo: Atlas, 2013. CVM - COMISSÃO DE VALORES MOBILIÁRIOS (Brasil). Cartilha de Governança Corporativa. Rio de Janeiro: Cvm, 2002. 13 p. Disponível em: http://conteudo.cvm.gov.br/export/sites/cvm/decisoes/anexos/oool/3935.pdf. Acesso em: I2 mar. 202I.

GARCIA, F. A. Governança corporativa. Rio de Janeiro: Universidade Federal do Rio de Janeiro, 2007

IBGC - INSTITUTO BRASILEIRO DE GOVERNANÇA CORPORATIVA (Brasil). Código das melhores práticas de governança corporativa. 5. ed. São Paulo: Ibgc, 2015. 103 p. Disponível em: https://edisciplinas.usp.br/pluginfile.php/4382648/mod_resource/content/r/Livro_Codig o_Melhores_Praticas_GC.pdf. Acesso em: Io mar. 2021.

JORNAL CONTÁBIL: Até que ponto você pode ser responsável pela fraude contábil. [S.L], or jan. 2or6. Disponível em: https://www.jornalcontabil.com.br/ate-que-ponto-vocepode-ser-responsavel-pela-fraude-contabil. Acesso em: Io mar. 202I.

LETHBRIDGE, E.. Governança corporativa. Revista Bndes, [S.L.], v. 4, n. 8, p. 209-23I, or jun. I997. Semestral. Disponível em: https://web.bndes.gov.br/bib/jspui/bitstream/1408/13435/r/RB\%2008\%20Governan\%C3 \%A7a\%20corporativa_P_BD.pdf. Acesso em: 03 mar. 2021.

MORAES, A. Iniciação ao estudo da administração. 2. ed. São Paulo: Pearson Education, 2001. 
OLIVEIRA, D. Governança corporativa na prática. 3. ed. São Paulo: Atlas, 2007.

SILVEIRA, Alexandre di Miceli da. Governança corporativa, desempenho e valor da empresa no Brasil. 2002. 165 f. Dissertação (Mestrado) - Curso de Administração, Faculdade de Economia, Administração e Contabilidade, Universidade de São Paulo, São Paulo, 2002. Disponível em: https://www.teses.usp.br/teses/disponiveis/12/12139/tde-04122002I02056/publico/Dissertacao_Alexandre_Di_Miceli.pdf. Acesso em: ro mar. 2021.

SILVEIRA, Alexandre di Miceli da. Governança corporativa no Brasil e no mundo: Teoria e prática. Rio de Janeiro: Elsevier, 2010.

STEINBERG, H.et al. A Dimensão humana da governança corporativa. São Paulo: Gente, 2003.

ZDANOWICS, J. E. Finanças aplicadas para empresas de sucesso. São Paulo: Atlas, 2012. 